\title{
New Mechanisms of Perinatal Hypoxia and Perspectives of Pathogenesis-oriented Treatment
}

\author{
Larisa A. Balykova ${ }^{\ddagger}$, Ludmila V. Ledyajkina§, Vladimir A. Trofimov $\ddagger$, Alexei P. Vlasov $\ddagger$, Irina S. \\ Nazarova ${ }^{\ddagger}$, Victor V. Revin $\ddagger$ \\ ¥ National Research Ogarev Mordovia State University, Saransk, Russia \\ $\S$ Mordovia Republic Clinical Perinatal center, Saransk, Russia
}

Corresponding author: Larisa A. Balykova (larisabalykova@yandex.ru)

Received: 08 Jul 2017 | Published: 17 Jul 2017

Citation: Balykova L, Ledyajkina L, Trofimov V, Vlasov A, Nazarova I, Revin V (2017) New Mechanisms of Perinatal Hypoxia and Perspectives of Pathogenesis-oriented Treatment. BioDiscovery 20: e14945. https://doi.org/10.3897/biodiscovery.20.e14945

\begin{abstract}
Aim: to study the contribution of structura-functional hemoglobin $(\mathrm{Hb})$ disorders into perinatal hypoxia $(\mathrm{PH})$ pathogenesis and possibility of its indicators using for pharmacotherapy efficiency assessment.90 full-term newborns with $\mathrm{PH}$ and 30 healthy ones were examined by clinical methods and $\mathrm{Hb}$ spectroscopy. Further children were randomized on 2 groups, received standard therapy and additionally L-carnitine.The indices, indicating $\mathrm{Hb}$ affinity to oxygen (1355/1550)/ (1375/1580) and ability to bind them $(1355 / 1550)$ were less in hypoxia-affected newborns and got reduced at increased severity of $\mathrm{PH}$. The indices of $\mathrm{Hb}$ ability to reject ligands (1375/1580) and $\mathrm{Hb}$ conformative alterations (1375/1172) were higher in hypoxia-affected neonates and increased simultaneously to $\mathrm{PH}$ severity. It means that in severe $\mathrm{PH}$ oxygen binding to $\mathrm{Hb}$ becomes insufficient. We have established the correlation between $\mathrm{Hb}$ conformations and clinical features in newborns with $\mathrm{PH}$. Additional use of L-carnitine promoted restoration of $\mathrm{Hb}$ comformative properties and improvement of neurologic status.Our dates confirm the contribution of disorders of $\mathrm{Hb}$ structural and functional properties into $\mathrm{PH}$ pathogenesis and suggest, that $\mathrm{Hb}$ spectroscopy indices could be used as novel criteria of hypoxia severity and pharmaco-therapy efficiency.
\end{abstract}




\section{Keywords}

Perinatal Hypoxia, Pathogenesis-oriented Treatment, pharmacotherapy, L-carnitine

\section{Presented at}

World BioDiscovery Congress 2017

\section{Funding program}

No financial support.

\section{Grant title}

Iniiative research

\section{Ethics and security}

The study was approved by a local Ethic Commetee.

\section{Conflicts of interest}

No conflicts of interest. 